\title{
Correction to: Distributed Resource Search in Self-organising Networks
}

\author{
Muntasir Al-Asfoor and Maria Fasli
}

Correction to:

Chapter "Distributed Resource Search in Self-organising Networks" in: V. Mařík, J.L. Martinez Lastra,

P. Skobelev (Eds.): Industrial Applications of Holonic

and Multi-Agent Systems, LNAI 8062, https://doi.org/10.1007/978-3-642-40090-2_24

In the originally published version the affiliation of the author Muntasir Al-Asfoor was not correct. It was corrected to "University of Al-Qadisiyah, Diwaniya, Iraq".

\footnotetext{
The updated online version of this chapter can be found at https://doi.org/10.1007/978-3-642-40090-2_24

V. Mař́k, J.L. Martinez Lastra, P. Skobelev (Eds.): HoloMAS 2013, LNAI 8062, p. E1, 2018.

(C) Springer-Verlag Berlin Heidelberg 2013

https://doi.org/10.1007/978-3-642-40090-2_28
} 